\title{
Application of Risk Assessment to Cogeneration Source Planning In Restructured Power System
}

\author{
Dike, Damian Obioma; Etta,Chibueze; Izuegbunam, Fabian Izundu; Dike, \\ Blessing Chnemerem; Osuji,Uzoma andUkomadu, Juliet \\ Electrical and Electronic Engineering Department, Federal University of Technology, Owerri 460001, Nigeria.
}

\begin{abstract}
Nigeria very recently experienced a restructuring in her power system setup. This was done with the intention of involving private investors in the generation and distribution expansion plans in tandem with the country's millennium development goals. A major focus of the current energy debate is how to meet the future demand for electricity while meeting up with the high operational efficiency required in a deregulated power industry. Energy conservation and pollution minimization are central to such desired optimal operation in this new power structure. Problem arises when these generating stations are situated in unfavourable locations leading to high losses. Building cogeneration plants is a very efficient way of achieving large generation capacity, while reducing energy wastage and environmental pollution. This work assesses the risks involved in locating and sizing of cogenerating plants using Monte Carlo technique applied in MATLAB simulation environment. Results obtained are used to determine the benefits accruing to the utility companies when these cogeneration plants are connected to the grid. This is because it forms a major point of consideration in the planning of the generation system, particularly in deregulated systems where profit maximization is a key to surviving the competition
\end{abstract}

\section{Introduction}

In recent times, the interest of mainstream energy economists, researchers and policy makers are rekindled in modeling the determinants of energy demand functions within the context of emerging and developing countries. Initially, the state government issued a license covering mainly municipal areas in medium to large cities. The areas of franchises were limited to city limits. The electricity supply company had a few restrictions. They had to supply power to anybody who asked for it, and are required to abide by safety rules. The electricity quality parameters were set more or less by the machinery suppliers [1]. Emphasis has now shifted to electricity as an energy input with the economic importance of stimulating socio-economic and technological development in an economy. Equally important is the need to obtain accurate estimates of electricity demand parameters for the purpose of forecasting, demand management and policy analysis.

Electricity demand is characterized mainly by economic factors viz electricity prices and real income; while demographic factors such as population and urbanization; and environmental factors like climatic condition are often included as additional explanatory variables. In general, the dynamics of electricity demand and consumption are known to exhibit seasonality, mean-reversion, high volatility and spikes [2].

Energy plays an important role in the economic growth of both developed and developing countries. The growth hypothesis suggests that energy consumption is an indispensable component in growth, directly or indirectly as a complement to capital and labour as an input in the production process. Since production and consumption activities involve energy as an essential factor inputs, the relationship between energy consumption and economic growth has been a subject of greater inquiry as energy is considered to be one of the important driving force of economic growth in all economies. The question as to whether energy consumption has positive, negative or neutral impact on economic activities has motivated the interest of economists and policy analysts hence the need to find out the impact and direction of causality between energy consumption and economic growth. Nigeria today is one of the developing countries in Sub-Sahara Africa which is highly endowed with abundant natural resources including renewable and non-renewable potential energy resources. However, increasing access to energy has proved to be not only a continuous challenge but also a pressing issue [3]. The gloomy energy services provision in Nigeria have adversely affected the living standards of the population and aggravated energy poverty in the economy. The energy consumption mix of the country as at 2004 was dominated by oil (58\%), natural gas (34\%) and hydroelectricity (8\%). The proportion of oil in Nigeria's energy mix between 1984 and 2004 decreased from 77 to $58 \%$ [4].

The demand for electricity in Nigeria is squarely for industrial, commercial and residential purposes. Fig.1 provides the trend of electricity consumption along with its disaggregated components. By visual inspection, electricity consumption by the residential sector has dominated other sectors since 1978, while the industrial sector's demand has witnessed continuous downward trend. The fall in the industrial sector's demand for electricity can be attributed to inadequate power supply which has forced manufacturers to resort to privately 
generated electricity for powering their production processes. Given the recent reforms embarked on by government to revamp electricity supply in Nigeria, it becomes important to model the key drivers of electricity demand in Nigeria in order to obtain empirical insights for electricity demand and supply projection and policy analysis.

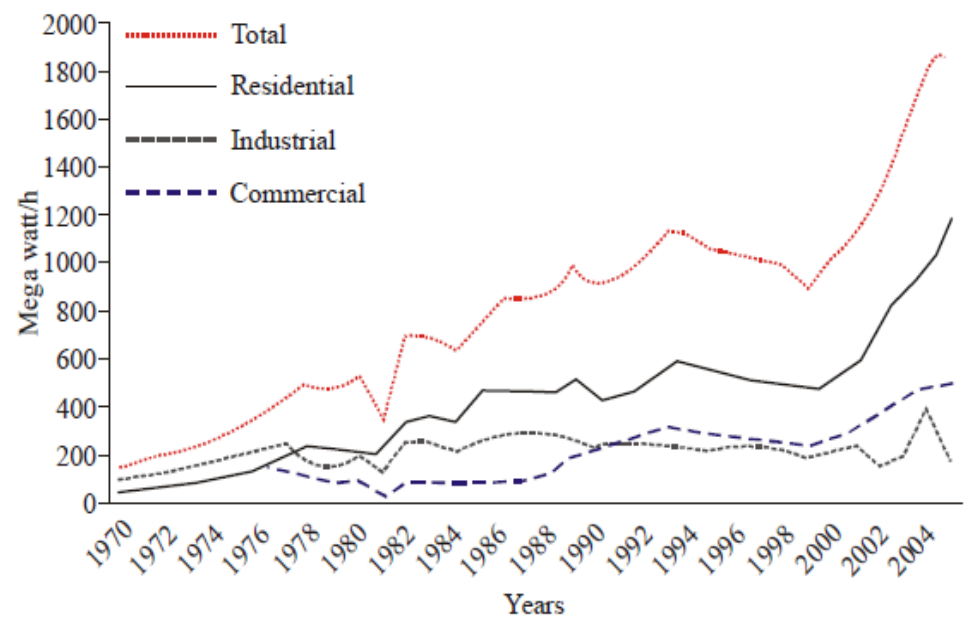

Fig1: Trend of electricity consumption in Nigeria (1970-2005) [5].

In the face of all these power challenges faced by the country, cogeneration offers some respite if tapped into. Cogeneration is an old concept that has been used even in the time of Thomas Edison. But the technology has improved greatly since then. Cogeneration is also known as Combined Heat and Power. It is the onsite production of multiple types of energy, usually heat and electricity from a single source of fuel [6]. Cogeneration technologies are classified either as topping for bottoming systems, depending on whether electric or thermal energy is produced first. In a topping system, electricity is produced first in the most common cogeneration mode and then the remaining thermal energy is used for such purposes as industrial processes, space heating and cooling, water heating, or even the production of more electricity. Topping systems would form the basis for residential/commercial, rural/agricultural, and most industrial cogeneration applications. While in a bottoming system, high-temperature thermal energy is produced first for applications such as steel reheat furnaces, glass kilns, or aluminum re-melt furnaces. Heat is extracted from the hot exhaust waste stream and transferred to a fluid (generally through a waste heat recovery boiler), which is then vaporized by the waste heat to drive a turbine that produces electricity. The primary advantage of bottoming cycles is that they produce electricity with waste heat (i.e., no fuel is consumed beyond that needed in the industrial process), but their use is limited to industries that need high temperature heat [7].

The paper is arranged in the following manner. Section II presents the model and explanation of the risk index and the simulation procedure. Section III contains the simulated results for the test system and accompanying discussions. Finally, the conclusion is given in section IV.

\section{Modeling Of The Risk Sensitivity Index}

In the study of how cogeneration plants react to increasing output, an index known as the Expected Energy Not Supplied (EENS) as given in equation (1) represents the risk. The idea is to obtain this index for an increasing output for the various cogeneration alternatives, then comparing the EENS to see whether it improves sharply or slightly.

EENS $=\sum_{i=1}^{N L}\left(\sum_{s \in F_{i}} \frac{n(s) C(s)}{N_{i}}\right) T_{i}$

Where, $\mathrm{C}(\mathrm{s})$ is the load curtailment (MW) in state s, NL is the number of load levels, $\mathrm{N}_{i}$ is the total number of samples, $\mathrm{T}_{i}$ is the time length of the $\mathrm{i}^{\text {th }}$ load level, $\mathrm{n}(\mathrm{s})$ is the number of states occurring in the sample, $\mathrm{F}_{i}$ the set of all the failure system states at the $\mathrm{i}^{\text {th }}$ load level. The simulation approach implemented using Matlab includes the following basic steps [8]:

(a) The multiple step annual load model is created, which eliminates the chronology and aggregates load states using hourly load records.

(b) The system states at a load level are selected using a Monte Carlo simulation process. The system under consideration is a composite generation and transmission system. 
Generating units are generally modeled using multiple state random variables, including the up, down, and de-rated states, whereas transmission components are represented using two-state variables (only up and down states) or are assumed to be $100 \%$ reliable, depending on the case. The inclusion of a transmission network is necessary since the effect of a generation addition may be limited due to constraints of the transmission network.

(c) Calculate the risk indices for the expected energy not supplied EENS. The risk indices are the numerical results of power system risk assessment.

(d) Steps 'b' and 'c' are repeated until convergence for each load level is attained.

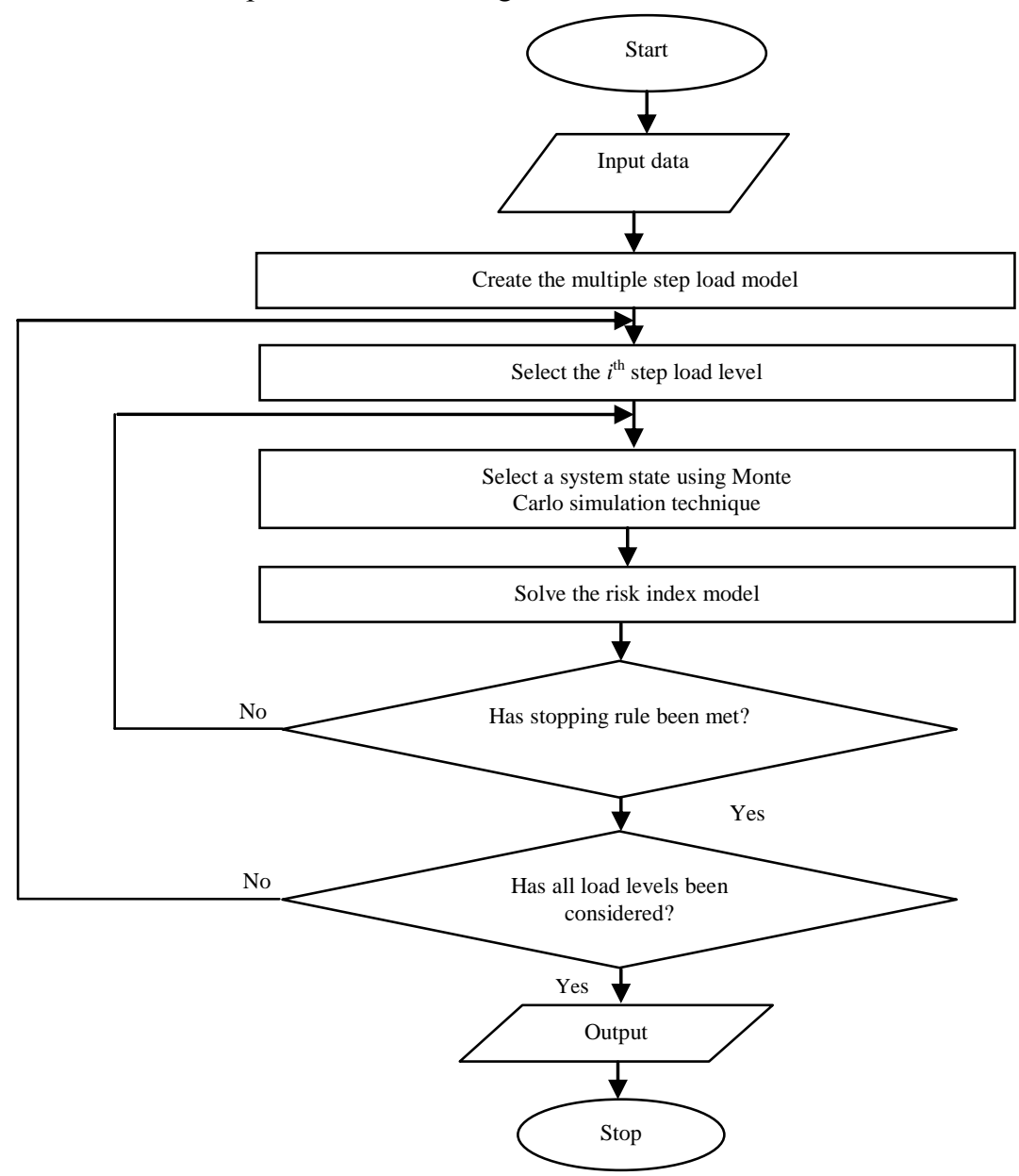

Fig. 2: Flowchart for application of risk assessment to cogeneration source planning

Based on the initial feasibility investigation, the potential locations and capacity ranges of cogenerators in the region are as follows [9]:

$>$ A 40-50MW hog-fuelled cogeneration facility of industrial customer A is connected to the $69 \mathrm{kV}$ system at Substation SCP.

$>$ An 80 or $150 \mathrm{MW}$ gas-fuelled cogeneration facility of industrial customer B is connected to the $69 \mathrm{kV}$ system at Substation IPM.

$>$ The same as in number 2 except that the cogenerator is connected to the $230 \mathrm{kV}$ system through a line to Substation CAM.

$>$ A $50-80 \mathrm{MW}$ gas-fuelled cogeneration facility of industrial customer $\mathrm{C}$ is connected to the $69 \mathrm{kV}$ system at substation UNY.

Maximum benefit analysis involves finding the cogeneration alternative that has a positive impact on the power utility company. This analysis is important to the utility due to an energy buy back policy i.e. purchasing back some of the output from the cogenerators by the utility for resale to other users because it is generally associated with revenue loss. This analysis is carried out based on the result from the risk sensitivity analysis. The relationship used to obtain the maximum net benefit is:

$\max N B=R R+L R+G R-E C$ 
Where $N B$ represents the net benefit, $R R$ is the reduction in the system risk cost; $L R$ is the reduction in the network loss cost, $G R$ is the reduction of total generation capacity requirement cost; $E C$ is the equivalent cost to the utility, which is the loss of revenue due to the access of cogeneration.

\section{Results And Discussion}

From the risk sensitivity analysis the following results were obtained for two different load levels:

Table I Annualized EENS (MWh/yr) for the four cogeneration locations at 1995 load level

\begin{tabular}{|c|c|c|c|c|}
\hline \multirow{2}{*}{$\begin{array}{c}\text { Cogenerator } \\
\text { Size } \\
(\mathrm{MW})\end{array}$} & \multicolumn{4}{|c|}{ Substation to be connected } \\
\hline & SCP & IPM & CAM & UNY \\
\hline 0 & 1325 & 1325 & 1325 & 1325 \\
\hline 10 & 1273 & 1294 & 1245 & 1190 \\
\hline 20 & 1252 & 1277 & 1169 & 960 \\
\hline 30 & 1230 & 1252 & 998 & 887 \\
\hline 40 & 1219 & 1236 & 920 & 840 \\
\hline 50 & 1209 & 1219 & 846 & 835 \\
\hline 60 & 1192 & 1208 & 753 & 835 \\
\hline 70 & 1189 & 1195 & 688 & 835 \\
\hline 80 & 1173 & 1190 & 624 & 835 \\
\hline 90 & 1160 & 1181 & 557 & 835 \\
\hline 100 & 1151 & 1172 & 553 & 835 \\
\hline 110 & 1147 & 1164 & 553 & 835 \\
\hline 120 & 1130 & 1157 & 551 & 835 \\
\hline 130 & 1123 & 1149 & 551 & 835 \\
\hline 140 & 1115 & 1136 & 551 & 835 \\
\hline 150 & 1115 & 1131 & 551 & 835 \\
\hline
\end{tabular}

It can be deduced from the results obtained as depict in Tables I and II that the cogeneration plant connected to the substation SCP yields little improvement in the system risk. The cogenerator of the customer B connected to the $69 \mathrm{kV}$ system at Substation IPM provides a much smaller improvement in the system risk when compared to the same connection made to the $230 \mathrm{kV}$ system at Substation CAM. The 50MW cogenerator connected to the $69 \mathrm{kV}$ system at Substation UNY provides a relatively significant improvement in the system risk but a larger unit beyond 50MW at the same substation does not lead to further improvement. Something similar also happens for the cogenerator connected to the $230 \mathrm{kV}$ system at Substation CAM; that is, the addition of the first 80MW provides a large improvement in the system risk, and anymore addition above 80MW has a limited further influence.

The observations can be explained as follows. Addition of a cogenerator can lighten (or even eliminate) some system problems caused by the outages that occur near the cogeneration location. The cogeneration cannot improve the system problems due to outages far away from it because of the transmission line constraint. This analysis suggests that the system risk is sensitive to locations and sizes of cogenerators; that is, an unsuitably located cogenerator may not provide an effective improvement in the system risk, although it increases the total generation capacity of the system.

Table II Annualized EENS (MWh/yr) for the four cogeneration locations at 2003 load level

\begin{tabular}{|c|cccc|}
\hline $\begin{array}{c}\text { Cogenerator } \\
\text { Size (MW) }\end{array}$ & \multicolumn{4}{|c|}{ Substation to be connected } \\
\hline 0 & SCP & IPM & CAM & UNY \\
\hline 10 & 9930 & 9930 & 9930 & 8930 \\
\hline 20 & 8831 & 9064 & 7779 & 6974 \\
\hline 30 & 8471 & 8727 & 6524 & 6129 \\
\hline 40 & 7919 & 8476 & 5428 & 5592 \\
\hline 50 & 7684 & 8240 & 4379 & 5250 \\
\hline 60 & 7544 & 8238 & 3371 & 5234 \\
\hline 70 & 7250 & 8049 & 2367 & 5234 \\
\hline 80 & 7015 & 7845 & 2180 & 5234 \\
\hline 90 & 6812 & 7650 & 2043 & 5234 \\
\hline 100 & 6593 & 7456 & 1956 & 5234 \\
\hline 110 & 6422 & 7317 & 1845 & 5234 \\
\hline 120 & 6270 & 7150 & 1758 & 5234 \\
\hline 130 & 6186 & 6962 & 1660 & 5234 \\
\hline 140 & 6115 & 6823 & 1573 & 5234 \\
\hline 150 & 5973 & 6823 & 1492 & 5234 \\
\hline
\end{tabular}

The comparisons drawn from the risk sensitivity analysis eliminates the cogenerators connected to the $69 \mathrm{kV}$ systems at Substations SCP and IPM. From the comparison also it is observed that cogeneration beyond 
$80 \mathrm{MW}$ connected to the $230 \mathrm{kV}$ system at Substation CAM provides almost no further improvement to the system reliability compared to the first $80 \mathrm{MW}$, so the maximum benefit analysis is used to ascertain if it is necessary to go beyond 80MW.

Table III Annualized EENS (MWh/yr) for the base generation and the two cogeneration schemes

\begin{tabular}{|c|c|c|c|}
\hline Year & Base case & Scheme 1 & Scheme 2 \\
\hline 1995 & 315 & 205 & 204 \\
\hline 1996 & 332 & 210 & 207 \\
\hline 1997 & 351 & 216 & 212 \\
\hline 1998 & 370 & 223 & 218 \\
\hline 1999 & 398 & 228 & 222 \\
\hline 2000 & 435 & 237 & 228 \\
\hline 2001 & 471 & 245 & 234 \\
\hline 2002 & 528 & 254 & 240 \\
\hline 2003 & 589 & 267 & 249 \\
\hline
\end{tabular}

This further assessment involves 2 schemes:

$50 \mathrm{MW}$ connected to the $69 \mathrm{kV}$ system at Substation UNY and $80 \mathrm{MW}$ connected to the $230 \mathrm{kV}$ system at Substation CAM

$>\quad 50 \mathrm{MW}$ connected to the $69 \mathrm{kV}$ system at Substation UNY and $150 \mathrm{MW}$ connected to the $230 \mathrm{kV}$ system at Substation CAM

Table III presents the annualized EENS for base generation and for the two cogeneration schemes in a five year period. The above data is used for an economic analysis known as the maximum benefit. For this analysis, a unit interruption cost of $\$ 6.3 / \mathrm{kWh}$ is assumed according to customer damage functions. Using the base generation system case as reference, the annual EENS index reduction and system risk cost reduction due to the two cogeneration schemes are calculated and tabulated as shown in Tables IV, V and VI.

Table IV Reduction in the annual EENS index (MWh/yr) due to the two cogeneration schemes

\begin{tabular}{|l|c|c|}
\hline Year & Scheme 1 & Scheme 2 \\
\hline 1995 & 110 & 111 \\
\hline 1996 & 122 & 125 \\
\hline 1997 & 135 & 139 \\
\hline 1998 & 153 & 158 \\
\hline 1999 & 170 & 176 \\
\hline 2000 & 198 & 207 \\
\hline 2001 & 226 & 237 \\
\hline 2002 & 274 & 288 \\
\hline
\end{tabular}

Table $\mathbf{V}$ Reduction in the system risk cost $(\mathrm{k} \$ / \mathrm{yr})$ due to the two cogeneration schemes.

\begin{tabular}{|c|c|c|}
\hline Year & Scheme 1 & Scheme 2 \\
\hline 1995 & 693 & 699 \\
\hline 1996 & 769 & 788 \\
\hline 1997 & 851 & 876 \\
\hline 1998 & 964 & 995 \\
\hline 1999 & 1071 & 1109 \\
\hline 2000 & 1247 & 1304 \\
\hline 2001 & 1424 & 1493 \\
\hline 2002 & 1726 & 1814 \\
\hline Total & $\mathbf{8 7 4 5}$ & $\mathbf{9 0 7 8}$ \\
\hline
\end{tabular}


Table VI Reduction in the network loss cost $(\mathrm{k} \$ / \mathrm{yr})$ due to the two cogeneration schemes.

\begin{tabular}{|l|c|c|}
\hline Year & Scheme 1 & Scheme 2 \\
\hline 1995 & 571 & 797 \\
\hline 1996 & 589 & 874 \\
\hline 1997 & 682 & 1018 \\
\hline 1998 & 760 & 1074 \\
\hline 1999 & 876 & 1269 \\
\hline 2000 & 744 & 1057 \\
\hline 2001 & 745 & 1083 \\
\hline 2002 & 660 & 972 \\
\hline Total & $\mathbf{5 6 7 2}$ & $\mathbf{8 1 4 4}$ \\
\hline
\end{tabular}

Index reduction $=($ base case $)-($ cogeneration scheme $)$

Risk cost reduction $=(\$ 6.3 / \mathrm{kWh}) \times$ (Index reduction)

Note that present value method is not used for purpose of simplicity. Also this risk cost evaluation is an approach that puts risk and economic factors on a unified scale of monetary value.

The access of a cogenerator to the utility system can reduce the system capacity requirements in generation-demand balance planning. This reduction, however, is not the megawatt value that can be provided by the cogenerator. The same capacity at major generation sources and cogeneration facilities does not create the same effect on system operation and system risk. The effect due to the cogenerator is limited to the local area, whereas that due to the major generation sources is more widespread and global. Generally, a discount coefficient is introduced to reflect this difference. The coefficient of 0.8 is used in this application.

\section{For Case 1:}

Reduction in system generation capacity: $(50+80-52) \times 0.8=62.4 \mathrm{MW}$ and reduction in capacity cost: 62.4 x $34=\$ 2122 \mathrm{k} /$ year. $52 \mathrm{MW}$ is the load of the cogeneration provider; $\$ 34 \mathrm{k} / \mathrm{MW} /$ year is the assumed rate of generation capacity.

\section{For Case 2:}

Reduction in system generation capacity: $(50+150-52) \times 0.8=118.4 \mathrm{MW}$ and reduction in capacity cost: 118.4 x $34=\$ 4026 \mathrm{k} /$ year. The $52 \mathrm{MW}$ is a deducted quantity from the system capacity reduction because the utility makes a commitment to guarantee the power supply for the cogeneration provider when its cogeneration facility fails.

Note that the major negative impact of cogeneration to utility is due to energy bought back. A buy back policy of $25 \%$ of nonutility generation output was assumed for this analysis, and the remaining percentage is wheeled to customers by the cogenerator. This $25 \%$ is still resold to other customers at no profit for the utility. But if this $25 \%$ of energy bought back was produced by the utility company and sold to customers, it would make an estimated profit of $\$ 32.75 / \mathrm{MWh}$. It means that the access of cogenerators to the power system results in a net revenue reduction to the utility. Historical statistics show that gas-fueled generators of 50MW and above have an average unavailability of 0.35 , inclusive of forced, planned, and maintenance outages. Using the calculated data from the previous calculations for schemes 1 and 2 :

\section{For Scheme 1}

Net revenue reduction: $(1-0.35)$ x $8760 \times(50+80-52) \times 32.75 \times 0.25=\$ 3636 \mathrm{k} / \mathrm{yr}$

Applying equation (2) to obtain the net benefits to the utility within the eight years for scheme 1

Net benefit $=8745+5627+(2122-3636) \times 8=\$ 2260 \mathrm{k}$

\section{For Scheme 2}

Net revenue reduction: $(1-0.35) \times 8760 \times(50+150-52) \times 32.75 \times 0.25=\$ 6900 \mathrm{k} / \mathrm{yr}$

Applying equation (2) to obtain the net benefits to the utility within the eight years for scheme 2

Net benefit $=9078+8144+(4026-6900) \times 8=-\$ 5770 \mathrm{k}$

From the results, it shows that scheme 1 yields a positive benefit while Scheme 2 yields a negative benefit. So it can be concluded that the best locations and sizes of cogenerators for the utility are 50MW connected to the $69 \mathrm{kV}$ system at Substation UNY and $80 \mathrm{MW}$ connected to the $230 \mathrm{kV}$ system at Substation CAM.

\section{Conclusion}

The application of risk evaluation to cogeneration source planning has successfully been implemented in this work. Besides the basic risk sensitivity, the additional analysis is required in planning the access of nonutility generators to the utility system. The following conclusions can be drawn: 
- Impact of nonutility generators: Generally, a nonutility generator creates both positive and negative impacts on the utility system. The impacts vary for different locations and sizes. In the given scenario, the first two locations of the cogenerators led to very limited improvement in the system risk. At the other two locations, the cogenerator can decrease the system risk, but when the size is beyond $50 \mathrm{MW}$ or $80 \mathrm{MW}$, it no longer provides further improvement. In the two cogeneration schemes selected from the preliminary risk sensitivity analysis, one can provide the utility with the positive benefit, whereas the other one results in the utility's economic loss.

- Impact of adding more generating units: Conceptually, addition of a generating unit will improve system reliability and thus reduce the system risk cost. The degree of the improvement totally depends on the location and size of added generating units. It is possible that a particular location may only create a very marginal impact on system risk. It should be appreciated that the access of cogenerators to the utility system is also associated with other aspects such as operation issues and wheeling agreements. In other words, reliability planning is only one portion of the whole problem. However, the risk sensitivity analysis and the overall economic assessment, including the risk cost, provide important information for decision making. If a zero or negative benefit cogeneration scheme (such as scheme 2) is presented in the negotiation, for example, a high access charge fee should be considered. Alternately, the proportion of energy bought back should be decreased.

The presented method can be utilized in different generation planning issues, including the comparison among different generation enhancement schemes and identification of the best location and size of cogenerators. It is important to recognize that, as in any other planning process, the risk evaluation and the economic analysis in generation planning are only necessary portions of the whole issue, although they may play a decisive role in the process.

\section{References}

[1]. M. Digambar. Tagare, "Electric Power Generation", IEEE Press, 2011.

[2]. N.U. Ekpo, C.A. Chuku, E.L. Effiong, "The Dynamics of Electricity Demand and Consumption in Nigeria", Maxwell Scientific Organization, August 15, 2011

[3]. Odularo, G. O. and Okonkwo, C. (2009), "Does Energy Consumption Contribute to Economic Performance? Empirical Evidence from Nigeria." Journal of Economics and International Finance, Vol. 1 (2), pp 044-058.

[4]. CBN Statistical Bulletin (2009)

[5]. Y.U. Dantata, Z.A. Yahaya, NasiruInuwa, "Energy Consumption and Economic Growth Nexus in Nigeria", European Scientific Journal, June 2010.

[6]. J. Puncochar, "Evaluating Cogeneration for Your Facility", Technical Information from Cummins Power Generation Incorporated, 2008.

[7]. "Edison Electric Institute, Statistic Year Book of the Electric Utility Industry" Washington, D. C. Edison Electric Institute.

[8]. W. Li, "Risk Assessment of Power Systems", IEEE Press, 2005.

[9]. Canadian Electricity Association, Generation Equipment Status Annual Report, Equipment Reliability Information Systems, 2012. 